\title{
Patterns of dioxin-altered mRNA expression in livers of dioxin-sensitive versus dioxin-resistant rats
}

\author{
Monique A. Franc $\cdot$ Ivy D. Moffat · Paul C. Boutros • \\ Jouni T. Tuomisto $\cdot$ Jouko Tuomisto $\cdot$ \\ Raimo Pohjanvirta $\cdot$ Allan B. Okey
}

Published online: 29 May 2008

(C) Springer-Verlag 2008

\section{Erratum to: Arch Toxicol}

DOI 10.1007/s00204-008-0303-0

There is a typographical error in one of the numerical entries in the Venn diagram. The value in the lower circle ("LnC") under the "Sensitive Collective" should read " 0 " rather than the erroneous value of " 90 " which was in the version of Fig. 3 that was originally published.

The authors apologize for this mistake.

The online version of the original article can be found under doi:10.1007/s00204-008-0303-0.

M. A. Franc · I. D. Moffat · P. C. Boutros · A. B. Okey $(\bowtie)$

Department of Pharmacology and Toxicology,

Room 4302, Medical Sciences Building, University of Toronto,

1 King's College Circle, Toronto, ON, Canada M5S 1A8

e-mail: allan.okey@utoronto.ca

Present Address:

M. A. Franc

Department of Pharmacogenomics, Johnson \& Johnson,

Pharmaceutical Research and Development,

1000 Route 202 South, P.O. Box 300, Raritan, NJ 08869, USA

\section{J. T. Tuomisto $\cdot$ J. Tuomisto}

Department of Environmental Health, Centre for Environmental

Health Risk Analysis, National Public Health Institute,

70701 Kuopio, Finland

\section{R. Pohjanvirta}

Department of Food and Environmental Hygiene,

Faculty of Veterinary Medicine, University of Helsinki,

00014 Helsinki, Finland

\section{Sensitive \\ Collective}

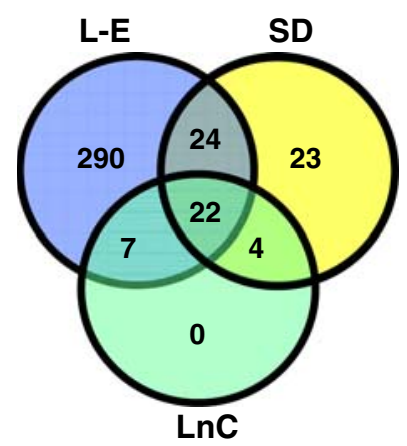

Resistant

Collective

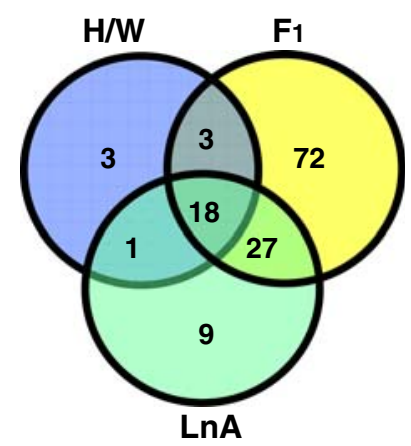

Fig. 3 Summary of the number of TCDD-responsive UniGene clusters within the collective of dioxin-sensitive rats and the collective of dioxin-resistant rats as detected on OCI cDNA arrays The numbers in each sector of the Venn diagrams represent the numbers of UniGene clusters whose expression was significantly affected $(P<0.05)$ by TCDD treatment in each rat strain or line. Data were obtained from experiments with OCI cDNA arrays as described in "Materials and methods" 